\title{
Recognition and adsorption of uranyl ion by ion imprinted polymer based materials
}

\author{
Jin $\mathrm{Bai}^{1, *}$,Yang $\mathrm{Yi}^{1}, \quad$ Xilin $\mathrm{Xiao}^{1}, \mathrm{Yi} \mathrm{Ge}^{1}$ \\ ${ }^{1}$ School of chemistry and chemical engineering, Nanhua Universityt, 421000, PRC
}

\begin{abstract}
Ion imprinted polymer is a kind of three-dimensional material with special cavity structure. Its cavity site has the function of specifically recognizing and binding target ions. It is a kind of materials that can selectively combine, enrich and remove target ions in the environment. Uranium is an important radioactive element, which has been widely used in nuclear power, military industry, science and technology and other fields. However, the accumulation of uranyl ions in environmental water causes serious health hazards to human body. Therefore, the detection and enrichment of uranyl ions in water is of great significance. In this paper, the theory, technology and application status of ion imprinted polymer for micro detection and adsorption of uranyl particles in wastewater were reviewed, and the development of uranyl ion imprinted polymer was prospected.
\end{abstract}

\section{Introduction}

With the rapid development of economy, the demand for energy in the world is more and more intense. As a renewable and clean energy, nuclear energy has been widely interested and vigorously developed. Uranium is a kind of radioactive heavy metal element, which is widely used in nuclear power generation, nuclear weapon manufacturing, nuclear activation analysis and other fields. In the process of nuclear energy application, uranium containing dust, uranium containing sewage and other wastes will be produced. If the nuclear waste is not fully treated and discharged, it will cause serious pollution to the environment and endanger human health. When insoluble uranium dust is inhaled by human body, uranium compounds will enter the blood and cause damage to human body. Uranyl ion in uranium containing wastewater is easy to enter the human body along with the food chain. With the accumulation of uranyl ion, it can cause systemic diseases and multiple organ canceration. Therefore, it is very important to detect the content of uranyl ion in the environment and to enrich and remove it. At present, the removal methods of radioactive uranium in wastewater include adsorption, membrane separation, ion permeation, reverse osmosis, and so on

Chemical precipitation, etc. Among them, adsorption method is widely used because of its simple operation, high efficiency, high cost performance, and be not easy to cause secondary pollution. At present, the detection methods of uranyl particles in wastewater mainly include ion chromatography, spectrophotometry, fluorescence, seed activation analysis, etc. These methods have the advantages of high sensitivity and low detection limit, but their application requires high cost and expensive equipment. Electrochemical method has attracted wide attention because of its high sensitivity, simple operation and low price.

Ion imprinted polymers (IIPs) are a kind of materials with three position cavity structure, which can specifically combine with target ions, and have both specific recognition and selective adsorption. In recent years, IIPs have been widely used in electrochemical sensor systems because of their simple preparation, good stability and low price. Because of their high sensitivity and low detection limit, IIPs have been widely used in metal ion selective electrochemical sensors. At the same time, IIPs have strong adsorption capacity for target ions, so IIPs can be used as an excellent material for the detection and adsorption of uranyl ions.

\section{Preparation of ion imprinted polymer}

When the template ion and the functional monomer are physically self-assembled, the template ion will be surrounded by the monomer to form a chelate and fixed. After the cross-linking polymerization, the imprinted cavity with the same size and shape as the template ion is obtained by eluting the template ion in the polymer, and the obtained polymer can specifically bind with the template ion.

The preparation methods of IIPs can be mainly divided into: (1) template ions and functional monomers are mixed in suitable solvents to form covalent or noncovalent complexes; (2) polymers are formed in the presence of crosslinkers and initiators; (3) template ions are removed by appropriate elution methods to obtain cavity structures with specific recognition function ( As shown in Figure 1) 


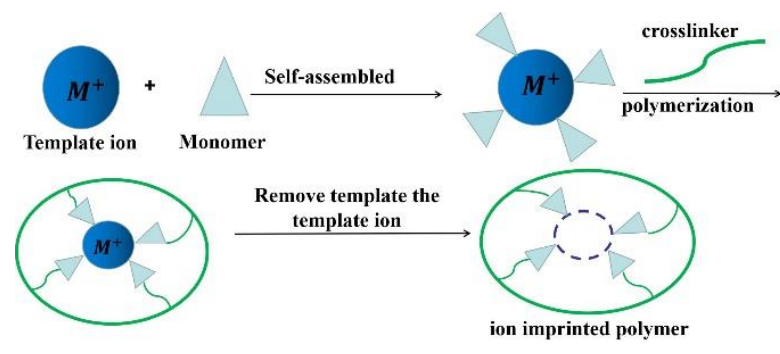

Fig. 1 Preparation of ion imprinted polymer

\section{Application of Ion Imprinted Electrochemical sensor (iip-ce) to the determination of uranyl ion in Wastewater}

The sensor will output signals after being stimulated by external physical or chemical stimuli. The electrochemical sensor can detect the concentration of uranyl ion in wastewater according to the changes of different electrochemical signals such as current, voltage and electrochemical impedance. Specific electrochemical sensors can be divided into voltammetry, impedance measurement and potential measurement. Wang et al. Constructed an ion imprinted electrochemical sensor with graphene modified carbon paste electrode, which can be used for the selective detection of trace uranyl ions. Using isophthalaldehyde-tetrapyrrole (IPTP) as the U ligand of uranyl ion, APTMS as the functional monomer and TEOS as initiator, the ion imprinted polymer was prepared by gel sol-gel method and modified on the surface of the graphene carbon paste electrode (GR-CPE) and then eluted to obtain uranyl ion sensor (IIP-GR-CPE). The linear range of uranyl ion detection is $1.0 \times$ molto 1.0 $\times$ The recoveries were $97.3 \%$ - 102.9\%. Majid kalate bojdi [2] and others developed an IIP carbon paste electrode (IIP CPE) sensor based on the high selectivity of IIP nanoparticle technology and the high sensitivity of differential pulse adsorption cathodic stripping voltammetry (dp-adcsv). Methacrylic and phenolic uranyl ligands were selected as functional monomers, EGDMA and AIBN as crosslinking agents and initiators, and the iip-cpe was constructed by precipitation polymerization. The detection limit was $0.03 \mu \mathrm{g}$ and the linear range was $0.1 \mu \mathrm{g}$ to $10 \mu \mathrm{g}$

Sevgi G ü Ney et al. [3] uranyl ion imprinted polymer (U-imp) and non uranyl ion imprinted polymer (N-imp) were synthesized by sol-gel copolymerization, and then modified on carbon paste electrode to obtain U-imp/CE.

Compared with the paste electrode containing n-imp, the paste electrode containing $\mathrm{u}$-imp has higher reduction peak current. The selectivity of electrochemical sensor can ensure that it has a good application prospect in the detection of actual samples.

The application of ion imprinted polymers in the adsorption of uranyl ions in sewage: the imprinted polymer prepared by sol-gel method has the advantages of good mechanical effect, high repetition rate and good stability. The memory cavity structure formed during the preparation process can selectively adsorb specific ions in complex environment, and plays an important role in the adsorption of uranyl ions in sewage. Thayyath $s$. anirudhan [4] reported a new type of uranyl ion imprinted polymer. Using 4-vinylpyridine as functional monomer and 2,20-azobisisobutyronitrile as initiator, IIPs were prepared by bulk polymerization, and non imprinted polymer (NIP) was prepared under the same conditions. The results show that $\mathrm{u}$ (VI) - IIP has better selectivity and adsorption capacity. When $\mathrm{pH}=7$ and temperature is $30{ }^{\circ} \mathrm{C}$, the equilibrium adsorption capacity is $133.95 \mathrm{mg} /$ g, u (VI) - IIP

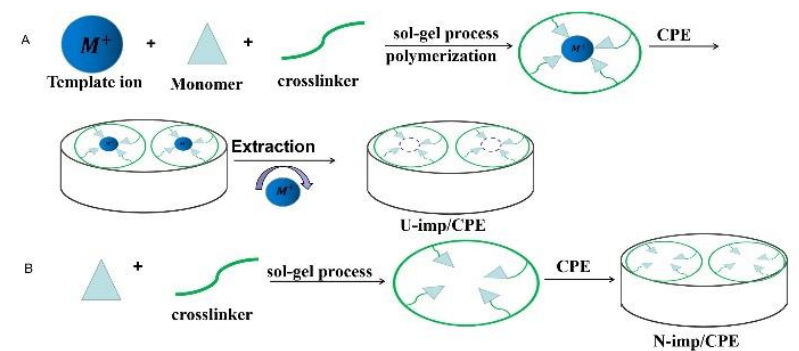

Fig. 2 Preparation of ion imprinted polymer

It has the potential to remove and recover U (VI) from wastewater. 5. E. pakade [5] et al. Prepared a novel acyl ion imprinted polymer by a simple and mild method, using 1 - (prop-2-en-1-yl) - 4 - (pyridin-2-ylmethyl) piperazine (ppmp) and MAA as functional monomers, edgma and accn as crosslinking agents and initiators, the optimal adsorption $\mathrm{pH}$ was $4.0 \sim 8.0$, the amount of adsorbent was $20 \mathrm{mg}$, the contact time was $20 \mathrm{~min}$, and $120 \mathrm{mg}$ uranyl ion was retained per g IIP. Hu Meng [6] and others introduced a $\mathrm{Si}$ coated graphene oxide modified $\mathrm{U}$ (VI) imprinted polymer (go Si / IIP). Through intermittent experiments, compared with go Si / nip, it was found that the maximum adsorption capacity of go $\mathrm{Si} /$ IIP was 17.89 mgg-1, which was higher than $10.32 \mathrm{mgg}-1$ of go Si / nip, indicating that the ionic imprinted composite material had better adsorption performance.

After five adsorption desorption cycles, go / sio2-iip can be efficiently regenerated and reused, which shows that it has a good removal effect on template ions. The disadvantage of go $\mathrm{Si} /$ IIP is that the preparation process is cumbersome. The development and preparation of simple and efficient IIP composites is the focus of future research. 
Table 1. Application of ion imprinted polymers in selective recognition and adsorption of other metal ions

\begin{tabular}{|c|c|c|c|c|}
\hline Adsorbed ion & synthetic method & $\begin{array}{l}\text { Decorative } \\
\text { materials }\end{array}$ & $\begin{array}{l}\text { Maximum adsorption } \\
\text { capacity }(\mathrm{mg} / \mathrm{g})\end{array}$ & reference \\
\hline $\mathrm{Cu}^{2+}$ & Copolymerization & $\mathrm{SiO}_{2}$ & 71.400 & 【 【9】 \\
\hline $\mathrm{Cu}^{2+}$ & $\begin{array}{c}\text { Surface } \\
\text { Imprinting }\end{array}$ & - & 39.82 & 【10】 \\
\hline $\mathrm{Cu}^{2+}$ & Copolymerization & $\begin{array}{c}\text { Magnetic } \\
\text { nanoparticles } \\
\mathrm{Fe}_{3} \mathrm{O}_{4}\end{array}$ & 50.38 & 【11】 \\
\hline $\mathrm{Pb}^{2+}$ & $\begin{array}{c}\text { Surface } \\
\text { Imprinting }\end{array}$ & $\begin{array}{l}\text { Sulfhydryl } \\
\text { group }\end{array}$ & 68.03 & 【 $12 】$ \\
\hline $\mathrm{Pb}^{2^{+}}$ & Copolymerization & Schiff Base & 54.9 & 【 $13 】$ \\
\hline$C d^{2^{+}}$ & Surface Imprinting & $\begin{array}{l}\text { Magnetized } \\
\text { carbon } \\
\text { nanotubes }\end{array}$ & - & 【14】 \\
\hline$C d^{2^{+}}$ & Copolymerization & $\begin{array}{l}\text { Mesoporous } \\
\text { silicon }\end{array}$ & 32.9 & [ 15$]$ \\
\hline$C d^{2^{+}}$ & Surface Imprinting & - & 38.30 & 【16】 \\
\hline $\mathrm{Hg}^{2^{+}}$ & Surface Imprinting & $\mathrm{Fe}_{3} O_{4} @ \mathrm{SiO}_{2}$ & 78.3 & 【17】 \\
\hline $\mathrm{Cr}^{2^{+}}$ & Surface Imprinting & MGO & 311.95 & 【18 \} $\\
{\hline T h^{4^{+}}} &{\text {Copolymerization }} &{\text { - }} &{33.3} &{\text { [19] }} \\
{\hline A u^{3^{+}}} &{\text {Copolymerization }} &{\text { Chitosan-MB }} &{195 \pm 0.5} &{\text { 【20】 }} \\
$\hline
\end{tabular}

Magnetic nanomaterials (NMPs) are special materials with both magnetic properties and nanostructures. Magnetic nanomaterials have superparamagnetism, magnetic single domain structure and other special magnetic properties. They can be uniformly dispersed in aqueous solution and rapidly separated from wastewater solution with the help of external magnetic field. Therefore, magnetic nanomaterials are a kind of adsorbent with good development prospects, The adsorption of uranyl ion by several magnetic nanomaterials is listed in Table 2.

Table 2. Application of ion imprinted polymers in selective recognition and adsorption of other metal ions

\begin{tabular}{|l|l|l|}
\hline Type of adsorbent & \multicolumn{1}{|c|}{$\begin{array}{c}\text { Maximum adsorption } \\
\text { capacity (mg/g) }\end{array}$} & reference \\
\hline CB/GO/Fe3O4 & 66.81 & {$[21]$} \\
\hline Fe3O4@TiO2 & 97.08 & {$[22]$} \\
\hline $\begin{array}{l}\text { Novel magnetic graphene } \\
\text { oxide }\end{array}$ & 113.27 & {$[21]$} \\
\hline Fe3O4@SiO2@Ni-L & 129.26 & {$[22]$} \\
\hline $\begin{array}{l}\text { Amidoxime functionalization } \\
\text { Fe3O4@SiO2 Core shell } \\
\text { magnetic microspheres }\end{array}$ & 160.00 & {$[23]$} \\
\hline $\begin{array}{l}\text { Amino modified Fe3O4/ } \\
\text { SiO2 Composites }\end{array}$ & 170.00 & {$[24]$} \\
\hline $\begin{array}{l}\text { Titanate nanotubes/cobalt } \\
\text { ferrite / } \\
\text { tetraethylenepentamine } \\
\text { (TNTs/CoFe2O4/TEPA) }\end{array}$ & 465.95 & {$[25]$} \\
\hline
\end{tabular}

At present, the adsorption effect of some magnetic nano materials for uranyl ion is satisfactory, but the selectivity for uranyl ion is not high, so the development of magnetic nano composite modified ion imprinted polymer has a good application prospect. At present, there are few reports on the adsorption and removal of uranyl ions by magnetic nanomaterials modified ion imprinted polymers, mainly involving the selective and efficient adsorption of. Xiao [26] and others introduced a kind of magnetic graphene oxide composite metal ion imprinted polymer, which was used for selective adsorption and synthesis. Using dopamine (DA) as the functional monomer, the imprinted polymer was synthesized by surface imprinting technology. Compared with the adsorption effect of [7-9] and [10-11], MIPs have larger adsorption capacity, stronger selectivity and stability. FARZANEH abdollahi [27] et al. Reported a novel ion imprinted polymer based on core-shell structure, Fe3O4@SiO2@TiO2 The modified IIP was used to detect the serum concentration of patients with gallstones, and the dynamic linear range was $0.20 \sim 28.00 \mu \mathrm{GL}-1$, the detection limit was $0.05 \mu \mathrm{g} \mathrm{L}-1$ 。 The modification of magnetic nanoparticles enhances the affinity of imprinted polymers, which is a promising selective adsorbent.

\section{Conclusion}

Ion imprinted polymers (IIPs) can realize the specific recognition and adsorption of target ions. They have stable structure, strong regeneration and high reuse rate. They can be used for enrichment and recovery of heavy metal ions such as uranyl ions in environmental water, and widely used in electrochemical sensors due to their high sensitivity and low detection limit. However, IIPs have some functions in synthesis, and there are few kinds of monomers, which lead to their performance can not meet the ideal requirements; Moreover, IIPs composites have some problems, such as high cost, complicated preparation process . Generally speaking, the current ionic imprinting materials are still in the development stage. Using green new materials, simplifying the preparation process of IIPs, developing new functional monomers, improving the performance of ionic imprinted polymers, studying the preparation of magnetic ionic imprinted polymers and large-scale industrial application will be one of the future research directions.

\section{Acknowledgments}

Thank you for the financial support of the innovation training program of Nanhua University, project number: x202010555322

\section{References}

1. Wang, Z. Zhang,D. Xiao,X. Su,C.Li, Z. Xue ,J. Peng,P. Liao,L. Wang,H.(2020)A highly sensitive and selective sensor for trace uranyl (VI) ion based on a graphene-coated carbon paste electrode modified with ion imprinted polymer.Microchemical Journal,155:0026-265X.

2. Majid , K. Mohammad, B.Mostafa, N.Akbar, B.Fariborz, O.Sara, S.(2015)Selective and Sensitive Determination of Uranyl Ions in Complex Matrices by Ion Imprinted Polymers-Based Electrochemical Sensor.Electroanalysis, 27: 2458 - 2467. 
3. Sevgi ,G. Orhan ,G .(2016)A novel electrochemical sensor for selective determination of uranyl ion based on imprinted polymer sol-gel modifified carbon paste electrode.Sensors and Actuators B Chemical http://dx.doi.org/10.1016/j.snb.2016.02.119.

4. Thayyath ,A. Jayachandran ,N. Peethambaran ,L. Divya.(2014)Adsorption and separation behavior of uranium(VI) by 4-vinylpyridine-graftedvinyltriethoxysilane-cellulose ion imprinted polymer.Journal of Environmental Chemical Engineering,465: 1-10.

5. Bojdi M K, Behbahani M, Sahragard A, et al. A palladium imprinted polymer for highly selective and sensitive electrochemical determination of ultra-trace of palladium ions[J]. Electrochim Acta, 2014,149:108-116.

6. Metilda P, Prasad K, Kala R, et al. Ion imprinted polymer based sensor for monitoring toxic uranium in environmental samples[J]. Anal Chim Acta, 2007, 582(1):147-153.

7. V. E. Pakade, E. M. Cukrowska, J. Darkwa, G. Darko, N. Torto and L. Chimuka. ( 2012 ) Simple and effificient ion imprinted polymer for recovery of uranium from environmental samples. Water Science \& Technology, 65.4: 728-736.

8. Zhu,J. Liu,Q. Liu,J. Chen, R. Zhang,H. Yu,J. Zhang,M. Li,R. and Wang,J.(2018)A novel ion-imprinted carbon material induced by hyperaccumulation pathway for the selective capture of uranium.ACS Appl. Mater. Interfaces,DOI: 10.1021/acsami.8b09022.

9. Buhani, Narsito, Nuryono, et al . Desalination and Water Treatment, 2015, 55( 5) , 1240 .

10. R en ZQ, ZhuXY, Du J, et al . Applied Surface Science, 2018, 435, 574 .

11. Zhan,Y. Luo,X. Nie,S. et al . (2011)Selective Separation of $\mathrm{Cu}(\mathrm{II})$ from Aqueous Solution with a Novel $\mathrm{Cu}(\mathrm{II})$ Surface Magnetic Ion-Imprinted Polymer.Industrial \& Engineering Chemistry Research,50: 6355-6361.

12. Zhu B, Zhou L Y, Zhang Q, et al . Desalination and Water Treatment, 2017, 86, 231.

13. Fan H T, Sun X T, Li W X . Journal of Sol-Gel Science and Technology, 2014, 72(1) , 144.

14. Zargar Behrooz, Khazaeifar Ali, Microchimica Acta, 2017, 184 ( 11$), 4521$.

15. Li W M, He R, Tan L, et al Journal of SolGel Science and Technology, 2016, 78(3) , 1.

16. C. Feng, M. Li, M. Li, Q. Zeng, Q. Gan, H. Yang, Synthesis and characterization of a surface-grafted $\mathrm{Cd}$ (II) ion-imprinted polymer for selective separation of Cd (II) ion from aqueous solution, Applied Surface Science http://dx.doi.org/10.1016/j.apsusc.2015.01.201

17. Zhang Q G, Wu J Y, Luo X B . R SC Advances
2016, 6( 18) , 14916.

18. Liang Q W, Geng J J, Luo H J, et al . Journal of Molecular Liquids, 2017, 248, 767.

19. Liang,H.Chen, Q. Ma,J. Huang,Y.Shen,X.(2017)Synthesis and characterization of a new ionimprinted polymer for the selective separation of thorium(IV) ions at high acidity.RSC Adv., 2017, 7, 35394

20. M.Monier, DA Abdel-Latif, Fabrication of Au(III) ionimprinted polymer based on thiol-modifified chitosan, International Journal of Biological Macromoleculeshttp://dx.doi.org/10.1016/j.ijbiomac. 2017.07.098

21. SHAO L, WANG X, REN Y, et al. Facile fabrication of magnetic cucurbit[6]uril/graphene oxide composite and application for uranium removal[J]. Chemical Engineering Journal, 2016, 286: 311-319.

22. ZHANG Xiaofei. Synthesis of core/shell structural magnetic materials and their adsorption properties of uranium[D]. Harbin: Harbin Engineering University, 2014.

23. SHENG G, SHAO X, LI Y, et al. Enhanced removal of uranium( $\mathrm{VI}$ ) by nanoscale zerovalent iron supported on Na-bentonite and an investigation of mechanism[J]. Journal of Physical Chemistry A, 2014, 118(16): 2952-2958.

24. HU Jianbang, YUAN Yali, TANG Qiong, et al. Preparation and adsorption of uranyl( VI) of aminomodified magnetic $\mathrm{Fe} 3 \mathrm{O} 4 / \mathrm{SiO} 2$ composite materials[J]. Applied Chemical Industry, 2012, 41(12): 2067-2070, 2074.

25. ZHU J, LIU Q, LI Z, et al. Efficient extraction of uranium from aqueous solution using an aminofunctionalized magnetic titanate nanotubes[J]. Journal of Hazardous Materials, 2018, 353: 9-17.

26. Xiao, H.Cai,L.et al.(2020)Preparation of metal ion imprinted polymer on magnetic graphene oxide / mil101 (CR) surface and its selective adsorption of $\mathrm{Cu}$ ( $\|$ ) and $\mathrm{Pb}$ ( $\|$ ).CHINESE JOU R NAL OF APPLIED CHEMIST R Y,DOI: 10 . 11944 /j . issn . 1000-0518 . 2020 . 09 . 200028.

27. Farzaneh, A.et al.(2019)Application of selective solid-phase extraction using a new core-shellshellnmagnetic ion-imprinted polymer for the analysis of ultra-trace mercury in serum of gallstone patients.SEPARATION SCIENCE AND TECHNOLOGY,https://doi.org/10.1080/01496395.2 019.1651337. 